\title{
EFEITO DO VÍRUS DO MOSAICO DO TRIGO SOBRE O RENDIMENTO DE TRIGO E TRITICALE*
}

\section{MARISA DALBOSCO ${ }^{1}$, JUREMA SCHONS ${ }^{1}$, ARIANO M. PRESTES ${ }^{2} \&$ DILETA CECCHETTI $^{1}$}

\author{
${ }^{1}$ Faculdade de Agronomia e Medicina Veterinária, Universidade de Passo Fundo, Cx. Postal 611, CEP 99001-970, Passo \\ Fundo, RS, e-mail: schons@upf.tche.br; ²Embrapa Trigo, Cx. Postal 569, CEP 99001-970, Passo Fundo, RS
}

(Aceito para publicação em 30/08/2001)

Autor para correspondência: Jurema Schons

DALBOSCO, M., SCHONS, J., PRESTES, A.M. \& CECCHETTI, D. Efeito do vírus do mosaico do trigo sobre o rendimento em cultivares de trigo e triticale. Fitopatologia Brasileira 27:053-057. 2002.

\begin{abstract}
RESUMO
O vírus do mosaico do trigo (Soil-borne wheat mosaic virus - SBWMV), transmitido pelo fungo de solo Polymyxa graminis, é responsável por uma das principais viroses que afetam a produção de trigo (Triticum aestivum). Com o objetivo de avaliar os danos causados pelo SBWMV, foram conduzidos experimentos no campo experimental da Embrapa Trigo, em solo naturalmente infestado com o fungo vetor, utilizando as cultivares de trigo, BR 32, BR 23, Embrapa 120, OR 1, IAC 5-Maringá, Embrapa 27, Embrapa $16 \mathrm{e}$ as cultivares de triticale (Triticum secale) Embrapa 53 e Iapar 23 , em duas épocas de plantio. Foram avaliados a altura de plantas, o número de perfilhos, número de grãos por espiga, número de grãos por planta, peso de grãos e o peso de mil grãos. Os dados

foram submetidos à análise de variância comparando-se as médias pelo teste de Scott \& Knott a 5\%. Para a altura de plantas, houve redução de até 27,5\% na cv. IAC 5-Maringá. A cv. BR 32 apresentou redução de $25 \%$ no número de perfilhos em plantas sintomáticas, ao passo que a cv. OR 1 aumentou 32,4\% o número de perfilhos. $\mathrm{O}$ número de grãos por planta apresentou redução em torno de $49 \%$ nas duas espécies estudadas. A redução no peso de grãos por planta variou de sete a $56 \%$ em trigo e de 51 a $59 \%$ em triticale, para o peso de mil grãos a redução variou de quatro a $26 \%$ em trigo e 23 a $30 \%$ em triticale.

Palavras-chave adicionais: SBWMV, Polymyxa graminis, rendimento, experimento a campo.

\section{ABSTRACT \\ Effects of Soil-borne wheat mosaic virus on yield in wheat and triticale cultivars}

Soil-borne wheat mosaic virus (SBWMV) is transmitted by the soil borne fungus Polymyxa graminis and is responsible for an important virus disease on wheat (Triticum aestivum). In order to evaluate the yield reduction in wheat due to SBWMV and in triticale, an experiment was carried out in naturally infested soil using wheat cultivars BR 32, BR 23, Embrapa 120, OR1, IAC 5Maringá, Embrapa 27, Embrapa 16 and triticale cultivars (Triticum secale) Embrapa 53 and Iapar 23. Seeds were sown at an experimental farm of the "Embrapa Trigo". The plant height, the number of tillers, the number of grains per spike, number of grains per plant, grain

weight and thousand grain weight were evaluated. The data were submitted to analysis of variance, comparing the average/medium with the Scott \& Knott at 5\% of probability. A reduction height of plants up to $27.5 \%$ was observed on the 'IAC 5-Maringá'. The number of tillers, in 'BR 32 ' showed a reduction of $25 \%$ in the symptomatic plants, while 'OR 1' increased the number of tillers in $32.4 \%$ under the same conditions. The weight reduction of grain per plant varied from seven to $56 \%$ in wheat and from 51 to $59 \%$ in triticale. The thousand-grain weight varied from four to $26 \%$ in wheat and from 23 to $30 \%$ in triticale.
\end{abstract}

\section{INTRODUÇÃO}

O vírus do mosaico do trigo (Soil-borne wheat mosaic virus - SBWMV) é responsável por uma das principais viroses que ocasiona a redução no rendimento de grãos de trigo (Triticum aestivum L.) e de outros cereais, sendo transmitido pelo fungo Polymyxa graminis Ledingham (Campbell, 1996). Polymixa graminis pertence à classe dos Plasmodiophoromycetos, apresentando zoosporos biflagelados e desiguais em tamanho (Menezes \& Oliveira, 1993); é considerado um parasita obrigatório comum das raízes de gramíneas (Chen

\footnotetext{
* Parte da Dissertação de Mestrado do primeiro autor. Universidade de Passo Fundo; bolsista da Capes
}

et al., 1998) e caracteriza-se por ser vetor de vírus (Campbell, 1996). O SBWMV pertence ao gênero Furovirus (Chen \& Wilson, 1995; Campbell, 1996) e apresenta genoma de RNA bipartido encapsidado em partículas alongadas retilíneas de fita simples e senso positivo (Murphy et al., 1995; Shirako, 1998).

Nykaza et al. (1979) observaram que os danos causados pelo SBWMV foram maiores quando a temperatura permaneceu abaixo de $17^{\circ} \mathrm{C}$ por longos períodos. Eversmeyer et al. (1983) constataram que temperaturas continuamente abaixo de $15{ }^{\circ} \mathrm{C}$, provavelmente, permitem conservar o SBWMV durante o desenvolvimento do trigo. Períodos com temperaturas acima de $15{ }^{\circ} \mathrm{C}$ estimulam o crescimento rápido do trigo e tendem a minimizar os danos. 
A redução no rendimento de grãos de 32 a $61 \%$ foi registrada, em Oklahoma, em 1952 (Wadsworth \& Yong, 1953). Em estudos subseqüentes, os mesmos autores avaliaram o efeito do SBWMV no rendimento de grãos, tendo sido registradas reduções de até $85 \%$. Resultados semelhantes foram observados por Bever \& Pendleton (1954) quando compararam o rendimento de 25 variedades de trigo cultivadas em áreas infestadas e não infestadas com o vetor, tendo registrado redução no rendimento de até $85 \%$.

No Brasil, há relatos de que o vírus causa reduções de até $50 \%$ na produtividade em cultivares de trigo (Caetano, 1982). Na região Sul do Brasil, ao longo dos últimos anos, tem sido observado um aumento na extensão das áreas tritícolas que exibem sintomas do SBWMV. Considerando a importância econômica da cultura do trigo e o reduzido número de trabalhos desenvolvidos nas condições brasileiras com relação aos efeitos do SBWMV sobre a produtividade, desenvolveu-se o presente estudo objetivando avaliar a redução no rendimento causado pelo SBWMV em trigo e triticale (Triticum secale Wittmack).

\section{MATERIAL E MÉTODOS}

O experimento de campo foi conduzido na área experimental da Embrapa Trigo em Passo Fundo, RS, sendo utilizadas duas espécies de cereais de inverno com diferentes reações de resistência ao SBWMV (Tabela 1). O experimento foi conduzido em duas épocas de semeadura (20/06 e 15/07/ 1998) em solo naturalmente infestado com P. graminis. O preparo, a adubação do solo e tratamentos fitossanitários seguiram as recomendações para a cultura (Recomendações da Comissão Sul-Brasileira de Pesquisa de Trigo, 1998).

O delineamento experimental utilizado foi inteiramente casualizado, com quatro repetições. Cada repetição constou de uma parcela com cinco linhas de $2 \mathrm{~m}$ de comprimento, espaçamento de $0,25 \mathrm{~m}$ entre linhas e densidade de 300 sementes aptas por $\mathrm{m}^{2}$.

No estádio de emborrachamento (Escala de FeeksLarge segundo Mehta, 1978), em cada parcela, nas três linhas

\begin{tabular}{cc} 
TABELA 1 - Reação de cultivares de trigo (Triticum \\
$\begin{array}{l}\text { aestivum) e triticale (Triticum secale) ao } \\
\text { SBWMV }\end{array}$ \\
\hline \hline Cultivar & Reação* \\
\hline Trigo & $\mathrm{MR}$ \\
cv. BR 32 & $\mathrm{S}$ \\
cv. BR 23 & $\mathrm{MR}$ \\
cv. Embrapa 120 & $\mathrm{S}$ \\
cv. OR 1 & $\mathrm{S}$ \\
cv. IAC 5-Maringá & $\mathrm{S}$ \\
cv. Embrapa 27 & $\mathrm{R}$ \\
cv. Embrapa 16 & \\
Triticale & $\mathrm{MR}$ \\
cv. Embrapa 53 & $\mathrm{S}$ \\
cv. Iapar 23 & \\
\hline
\end{tabular}

*MR - Moderadamente Resistente; R - Resistente; S - Suscetível Fonte: Recomendações da Comissão Sul-Brasileira de Pesquisa de Trigo (1998) centrais, marcaram-se aleatoriamente 20 plantas com sintomas da virose (condição I) e 20 plantas sem sintomas (condição II). Após a maturação, as plantas foram colhidas individualmente sendo avaliadas as seguintes características: a) altura de plantas, em centímetros a partir da superfície do solo até o ápice das espigas, excetuando-se as aristas; b) número de espigas por planta; c) número de perfillhos por planta; d) número de grãos por planta; e) número de grãos por espiga, quociente entre o número de grãos por planta e o número de espigas por planta; f) peso de grãos por planta a partir da pesagem do número de grãos por planta; g) peso de mil grãos. Os dados foram submetidos à análise de variância, comparando-se as médias pelo teste de Scott \& Knott a 5\% de probabilidade.

\section{RESULTADOS E DISCUSSÃO}

Observou-se interação entre cultivar e sintoma, excetuando-se a cv Embrapa 16, considerada resistente. Nas cultivares de trigo com sintomas da virose, houve redução na altura das plantas, as quais variaram de $27,5 \%$ na cv. IAC 5Maringá a 4,2\% na cv. Embrapa 16. Para as cultivares de triticale, a redução na altura foi de 9,5\% na cv. Embrapa 53 a $12,2 \%$ na cv. Iapar 23 . Esses resultados confirmam a resistência da cv. Embrapa 16 ao SBWMV (Barbosa, 1996), considerando que esta não apresentou redução significativa na altura das plantas com sintomas de mosaico quando comparadas às plantas assintomáticas. Isso indica que essa cultivar é pouco sensível aos efeitos do vírus no que se refere à altura de planta. Essa observação, possivelmente, esteja associada ao fato de que os mecanismos de replicação viral e do movimento do vírus são inibidos em cultivares resistentes, de acordo com Armitage et al. (1990).

O efeito do vírus sobre a altura das plantas nas cultivares brasileiras estudadas foi expressivo quando comparado aos efeitos encontrados por Campbell et al. (1975) e Nykaza et al. (1979) que observaram uma redução na altura das plantas infetadas com SBWMV de 4,7\% em genótipos suscetíveis, valor idêntico ao observado para o genótipo resistente (Embrapa 16) nas condições deste trabalho. Por outro lado, Hunger et al. (1989) encontraram valor semelhante ao observado no presente estudo, uma vez que relataram redução de 4,2\% na altura de plantas infetadas com SBWMV em um genótipo resistente.

Nas plantas de trigo, o número de perfilhos foi variável e diferenças significativas foram observadas para as cultivares BR 32, OR 1 e Embrapa 16. Foi observado que, nas cultivares OR 1, IAC 5-Maringá e Embrapa 27, a virose induziu um perfilhamento excessivo e que, nesses casos, o número de perfilhos foi superior nas plantas com sintomas, as quais apresentaram um aumento de $32,4 \%, 20 \%$ e $11,4 \%$, respectivamente, quando comparadas às plantas assintomáticas. Resultados semelhantes foram obtidos por Bockus \& Niblett (1984), Larsen et al. (1985) e Hunger \& Sherwood (1985) em cultivares de trigo suscetíveis que apresentavam infecção no início do seu desenvolvimento, tendo sido severamente atrofiadas e apresentando normalmente numerosos perfilhos. 
Efeito do vírus do mosaico do trigo sobre o rendimento...

Não foram observadas diferenças significativas no número de perfilhos nas duas cultivares de triticale estudadas entre plantas sintomáticas e assintomáticas. Entretanto, reduções significativas no número de perfilhos nas plantas sintomáticas em relação às assintomáticas foram observadas nas cultivares BR 32 e Embrapa 16 (25 e 20\%, respectivamente). Campbell et al. (1975) observaram, em Illinois, que as plantas de trigo severamente infetadas com SBWMV apresentavam um menor número de perfilhos quando comparadas às plantas não infetadas com o vírus. Nykaza et al. (1979) também verificaram uma redução no número de perfilhos de 11,8\% em plantas infetadas. Igualmente, Hunger et al. (1989), em estudo com uma cultivar de trigo resistente, observaram uma redução de $8,3 \%$ no número de perfilhos. Embora nas cultivares BR 32 e Embrapa 16 tenha sido observado redução no perfilhamento, na área experimental o número de plantas com sintomas foi extremamente reduzido quando comparado as demais cultivares, confirmando desta forma, os resultados em experimentos anteriores (Recomendações da Comissão Sul-Brasileira de Pesquisa de Trigo, 1998) que a cultivar Embrapa 16 é considerada resistente e BR 32 é moderadamente resistente ao SBWMV.

Os resultados encontrados vêm confirmar que o tipo de sintomatologia induzido pelo vírus é uma característica varietal, conforme mencionado anteriormente (Larsen et al., 1985), não havendo uma uniformidade na reação ao vírus nos diferentes genótipos.

Diferenças significativas em relação ao número de grãos por espiga entre as plantas sintomáticas e assintomáticas foram observadas nas duas cultivares de triticale e, em trigo, nas cultivares BR 32, BR 23, OR 1, IAC 5-Maringá e Embrapa 27. A redução do número de grãos induzida pelo SBWMV nas plantas variou de 1\% na cv. Embrapa 120 a 33,6\% na cv. OR 1. Apenas as cultivares Embrapa 120 e Embrapa 16 não apresentaram redução significativa do número de grãos por espiga em plantas com sintomas do vírus. Campbell et al. (1975) já haviam observado a redução no número de grãos por espiga em plantas de trigo infetadas pelo SBWMV.

$\mathrm{Na}$ primeira época (experimento I), as cultivares de triticale com sintomas do SBWMV apresentaram diferenças estatísticas quanto ao número de grãos por planta quando comparadas às plantas sem sintomas, com redução de $49,3 \%$ na cv. Iapar 23 e 39,5\% na cv. Embrapa 53. Entre as cultivares de trigo, observou-se uma redução no número de grãos por planta de 6,1 e 7,2\% na cv. Embrapa 120 e na cv. IAC 5Maringá, respectivamente. Nas demais cultivares, a redução promovida pelo vírus variou de 40 a $49 \%$ nas plantas sintomáticas em relação às assintomáticas (Tabela 2). Na cultivar Embrapa 16, considerada resistente, a redução no número de grãos por espiga foi significativa entre plantas sintomáticas e assintomáticas. Para a segunda época (experimento II), as cultivares de triticale apresentaram uma redução média de $30 \%$ e, nas cultivares de trigo, a redução variou de $9,9 \%$ na cv. Embrapa 27 a 49,2\% na cv. OR 1 nas plantas com sintomas em relação às plantas sem sintomas da virose.

Diferenças significativas com relação ao peso de grãos por planta entre plantas sintomáticas e assintomáticas também foram observadas nas duas cultivares de triticale nas duas épocas (Tabela 3). As cultivares de trigo BR 32, BR 23, OR 1, Embrapa 27 e Embrapa 16 apresentaram diferenças significativas na primeira época, com uma redução variando de $40 \%$ na cv. Embrapa 16 a $61 \%$ na cv. BR 23. As demais cultivares não apresentaram diferenças significativas para este componente de rendimento. Para a segunda época de plantio, nas cultivares BR 23, Embrapa 120, OR 1, IAC 5-Maringá e Embrapa 16, as plantas com sintomas apresentaram diferenças estatísticas em relação às plantas sem sintomas, com redução de 35,1 a $61,1 \%$ na BR 23 e OR 1, respectivamente. A cultivar Embrapa 27 não apresentou diferença significativa entre plantas sintomáticas e assintomáticas.

Da mesma forma que o observado para o número de grãos, o peso de grãos foi mais afetado na primeira época de plantio, sendo que, de maneira geral, as cultivares suscetíveis foram as que apresentaram maiores reduções. Segundo Chen

TABELA 2 - Efeito do SBWMV no número de grãos por planta em sete cultivares de trigo (Triticum aestivum) e duas cultivares de triticale (Triticum secale), com ausência (condição I) e presença de sintomas (condição II) da virose em duas épocas de plantio

\begin{tabular}{|c|c|c|c|c|c|c|}
\hline \multirow{2}{*}{ Cultivar } & \multicolumn{3}{|c|}{ Época 1} & \multicolumn{3}{|c|}{ Época 2} \\
\hline & Condição I ${ }^{*}$ & Condição II ${ }^{*}$ & Variação \%* & Condição I * & Condição II * & Variação \% * \\
\hline \multicolumn{7}{|l|}{ Trigo } \\
\hline BR 32 & A $257,1 \mathrm{a}$ & B 146,3 b & 43,1 & A 136,8 a & A 105,2 a & 23,1 \\
\hline BR 23 & A $122,4 \mathrm{~b}$ & B $62,3 \mathrm{~b}$ & 49,1 & A $157,0 \mathrm{~b}$ & B $115,4 \mathrm{a}$ & 26,5 \\
\hline Embrapa 120 & A $76,7 \mathrm{c}$ & A 72,3 a & 6,1 & A 188,5 b & B 144,0 a & 23,6 \\
\hline OR 1 & A $72,8 \mathrm{c}$ & A $41,0 \mathrm{~b}$ & 43,7 & A 114,6 b & B 58,2 b & 49,2 \\
\hline IAC-5 Maringá & A 53,9 c & A $50,0 \mathrm{~b}$ & 7,2 & A 141,3 b & B $82,3 \mathrm{~b}$ & 41,8 \\
\hline Embrapa 27 & A $109,0 \mathrm{~b}$ & B $62,6 \mathrm{~b}$ & 42,6 & A 141,9 b & A 127,8 a & 9,9 \\
\hline Embrapa 16 & A 160,4 b & B $95,4 \mathrm{~b}$ & 40,5 & A $135,8 \mathrm{~b}$ & B 84,7 b & 37,6 \\
\hline \multicolumn{7}{|l|}{ Triticale } \\
\hline Embrapa53 & A $143,8 b$ & B 87,0 a & 39,5 & A $185,8 \mathrm{~b}$ & B 127,0 a & 31,6 \\
\hline Iapar 23 & A $131,1 \mathrm{~b}$ & B $66,5 \mathrm{~b}$ & 49,3 & A $115,9 \mathrm{~b}$ & B $78,5 \mathrm{~b}$ & 32,2 \\
\hline
\end{tabular}

$\mathrm{CV}(\%) 22,14$

*Médias seguidas da mesma letra minúscula comparadas na coluna não diferem entre si pelo teste de Scott \& Knott e médias precedidas da mesma letra maiúscula comparadas na linha não diferem entre si pelo teste T ao nível de $5 \%$ de significância. 
\& Wilson (1995), o atraso no plantio da cultura reduz o número de plantas infetadas com o vírus em razão do curto período de temperatura e umidade ótimas, diminuindo a oportunidade de infecção pelo fungo.

Em experimentos conduzidos por Palmer \& Brakke (1975), foi observada uma redução de $35 \%$ no rendimento de cultivares de trigo suscetíveis ao SBWMV quando comparadas a cultivares resistentes. Diferenças na ordem de $48 \%$ foram encontradas por Campbell et al. (1975). Prestes \& Wiethölter (1993) encontraram redução na produtividade de 57\% na cultivar de trigo BR 23, suscetível ao SBWMV.

$\mathrm{Na}$ primeira época, as duas cultivares de triticale e todas as cultivares de trigo, que faziam parte do experimento para avaliação do peso de mil grãos (PMG), diferiram estatisticamente entre plantas sintomáticas e plantas assintomáticas, variando de 4,1\% na cv. Embrapa 16 a 26,2\% na cv. IAC 5Maringá. Nas cultivares de triticale, a redução foi de 30,5\% para cv. Embrapa 53 e 23\% na cv. Iapar 23 (Tabela 4). Na segunda época, as cultivares Embrapa 120, OR 1, IAC 5Maringá e Embrapa 27 diferiram estatisticamente quanto ao PMG nas plantas sintomáticas em relação às assintomáticas, com redução variando de $14 \%$ na cv. IAC 5-Maringá a 22,5\% na cv. Embrapa 27. A cultivar de triticale Iapar 23 apresentou uma redução de 29,8\% no PMG nas plantas sintomáticas em relação às assintomáticas (Tabela 4). Os resultados encontrados são semelhantes aos de Hunger et al. (1989), que observaram redução no PMG de até 18,8\% em cultivares suscetíveis.

As reduções observadas no PMG levam a concluir que a virose causada por SBWMVnão só causa a redução na produtividade como também interfere na qualidade do grão. Em observações realizadas no momento de análise das sementes, constatou-se que muitas sementes oriundas de plantas com sintomas da virose eram mal formadas e apresentavam tamanho reduzido.

TABELA 3 - Efeito do SBWMV no peso de grãos por planta em sete cultivares de trigo (Triticum aestivum) e duas cultivares de triticale (Triticum secale), com ausência (condição I) e presença de sintomas (condição II) da virose em duas épocas de plantio

\begin{tabular}{|c|c|c|c|c|c|c|}
\hline \multirow{2}{*}{ Cultivar } & \multicolumn{3}{|c|}{ Época 1} & \multicolumn{3}{|c|}{ Época 2} \\
\hline & Condição I* & Condição II* & Variação \% & Condição I* & Condição II* & Variação \% \\
\hline \multicolumn{7}{|l|}{ Trigo } \\
\hline BR 32 & A 9,4 a & B 4,6 a & 51,0 & A $5,4 \mathrm{c}$ & A 3,4 a & 37,0 \\
\hline BR 23 & A $4,1 \mathrm{~b}$ & B $1,6 \mathrm{c}$ & 61,0 & A $5,7 \mathrm{~b}$ & B 3,7 a & 35,1 \\
\hline Embrapa 120 & A $2,6 \mathrm{c}$ & A $2,4 \mathrm{~b}$ & 7,7 & A 7,0 a & B $4,5 \mathrm{a}$ & 35,7 \\
\hline OR 1 & A 2,5 c & B $1,1 \mathrm{c}$ & 56,0 & A $3,6 \mathrm{~d}$ & B $1,4 \mathrm{~b}$ & 61,1 \\
\hline IAC 5-Maringá & A $2,0 \mathrm{c}$ & A $1,4 \mathrm{c}$ & 30,0 & A $5,0 \mathrm{c}$ & B 3,0 b & 40,4 \\
\hline Embrapa 27 & A $3,0 \mathrm{c}$ & B 1,5 c & 50,0 & A $4,0 \mathrm{~d}$ & A 3,0 b & 25,0 \\
\hline Embrapa 16 & A 5,0 b & B 3,0 b & 40,0 & A $4,2 \mathrm{~d}$ & B 2,3 b & 45,2 \\
\hline \multicolumn{7}{|l|}{ Triticale } \\
\hline Embrapa 53 & A $5,5 \mathrm{~b}$ & B $2,7 \mathrm{~b}$ & 51,0 & A $7,1 \mathrm{a}$ & B 4,3 a & 39,4 \\
\hline Iapar 23 & A 5,2 b & B 2,1 b & 59,6 & A $4,8 \mathrm{c}$ & B 2,3 b & 52,1 \\
\hline CV (\%) 23,36 & & & & & & \\
\hline
\end{tabular}

TABELA 4 - Efeito do SBWMV sobre o peso de mil grãos em sete cultivares trigo (Triticum aestivum) e duas cultivares de triticale (Triticum secale), com ausência (condição I) e presença de sintomas (condição II) da virose em duas épocas de plantio

\begin{tabular}{|c|c|c|c|c|c|c|}
\hline \multirow{2}{*}{ Cultivar } & \multicolumn{3}{|c|}{ Época 1} & \multicolumn{3}{|c|}{ Época 2} \\
\hline & Condição I* & Condição II* & Variação \% & Condição I* & Condição II* & Variação \% \\
\hline \multicolumn{7}{|l|}{ Trigo } \\
\hline BR 32 & A $35,1 \mathrm{a}$ & B 28,2 a & 19,6 & A $37,2 \mathrm{~b}$ & A 35,9 a & 3,5 \\
\hline BR 23 & A $32,1 \mathrm{~b}$ & B $25,8 \mathrm{~b}$ & 19,6 & A $33,9 \mathrm{~b}$ & A $31,6 \mathrm{~b}$ & 6,8 \\
\hline Embrapa 120 & A 37,9 a & B 30,6 a & 19,2 & A 37,2 b & B $30,0 \mathrm{~b}$ & 19,3 \\
\hline OR 1 & A $33,7 \mathrm{~b}$ & B 27,4 a & 18,7 & A $31,6 \mathrm{c}$ & B 24,9 c & 21,2 \\
\hline IAC 5-Maringá & A $38,2 \mathrm{a}$ & B 28,2 a & 26,2 & A $36,3 \mathrm{~b}$ & B 31,2 b & 14,0 \\
\hline Embrapa 27 & A $27,8 \mathrm{c}$ & B $23,4 \mathrm{~b}$ & 15,8 & A $28,4 \mathrm{c}$ & B $22,0 \mathrm{c}$ & 22,5 \\
\hline Embrapa 16 & A $31,6 \mathrm{~b}$ & B 30,3 a & 4,1 & A 30,3 c & A $27,0 \mathrm{c}$ & 10,0 \\
\hline \multicolumn{7}{|l|}{ Triticale } \\
\hline Embrapa53 & A 39,6 a & B $27,5 \mathrm{a}$ & 30,5 & A $35,2 \mathrm{~b}$ & A 33,6 a & 4,5 \\
\hline Iapar 23 & A 39,6 a & B $30,5 \mathrm{a}$ & 23,0 & A $41,3 \mathrm{a}$ & B $29,0 \mathrm{~b}$ & 29,8 \\
\hline
\end{tabular}

CV (\%) 9,59

*Médias seguidas da mesma letra minúscula comparadas na coluna não diferem entre si pelo teste de Scott \& Knott e médias precedidas da mesma letra maiúscula comparadas na linha não diferem entre si pelo teste T ao nível de $5 \%$ de significância. 


\section{EFERÊNCIAS BIBLIOGRÁFICAS}

ARMITAGE, C.R., HUNGER, R.M., SHERWOOD, J.L. \& WEEKS D.L. Relationship between development of hard red winter wheat and expression of resistance to wheat soilborne mosaic virus. Plant Disease 74:356-359. 1990.

BARBOSA, M. M. Controle genético da resistência ao vírus do mosaico do trigo em Triticum aestivum L. Thell (Dissertação de Mestrado). Uberlândia. Universidade Federal de Uberlândia. 1996.

BEVER, W.M. \& PENDLETON, J.W. The effect of soil-borne wheat mosaic on yield of winter wheat. Plant Disease Reporter 38:266-267. 1954.

BOCKUS, W.W. \& NIBLETT, C.L. A procedure to identify resistance to wheat soilborne mosaic in wheat seedlings. Plant Disease 68:123-124. 1984.

CAETANO, V.R. Mosaico do trigo transmitido pelo solo "wheat soilborne mosaic virus" Tobamovirus. In: Osório, E.A. (Ed.) Fundação Cargill. Trigo no Brasil. Campinas, 1982. v.2, p.563570.

CAMPBELL, L.G., HEYNE, E.G., GRONAU, D.M. \& NIBLET, C. Effect of soilborne wheat mosaic virus on wheat yield. Plant Disease Reporter 59:472-476. 1975.

CAMPBELL, R.N. Fungal transmission of plant viruses. Annual Review Phytopathology 34:87-108. 1996.

CHEN, J. \& WILSON, T.M.A. Taxonomy of rigid rod-shaped viruses transmitted by fungi. Agronomie 15:421-426. 1995.

CHEN, J.,WANG, Z., HONG, J., COLLIER, C.R., \& ADAMS, M.J. Ultrastructural studies of resting spore development in Polymyxa graminis. Mycology Research 102:687-691. 1998.

EVERSMEYER, M.G., WILLIS, W.G. \& KRAMER, C.L. Effect of soil fumigation on occurrence and damage caused by soilborne wheat mosaic. Plant Disease 67:1000-1002. 1983.

HUNGER, R. M. \& SHERWOOD, J. L.Use of symptomatology and virus concentration for evaluating resistance to wheat soilborne mosaic virus. Plant Disease 69:848-850. 1985

HUNGER, R.M., ARMITAGE, C.R. \& SHERWOOD, J.L. Effects of wheat soilborne mosaic virus on hard red winter wheat. Plant Disease 73:949-952. 1989.

LARSEN, H.J., BRAKKE, M.K. \& LANGENBERG, W.G. Relationship between wheat streak mosaic virus and soilborne wheat mosaic virus, disease resistence, and early growth of winter wheat. Plant Disease 69:857-862. 1985.

MENEZES, M. \& OLIVEIRA, S.M.A. Fungos Fitopatogênicos. Recife: UFRPE, Imprensa Universitária. 1993.

MEHTA, Y. R. Doenças do trigo e seu controle. São Paulo: Agronômica Ceres, 1978.

MURPHY, F.A., FAUQUET, C.M., BISHOP, D.H.L., GHABRIAL, S.A., JARVIS, A.W., MARTELLI, G.P., MAYO, M.A. \& SUMMERS, M. D. Virus Taxonomy. Austria: Springer-Verlag. 1995.

NYKAZA, S.M., HEYNE, E.G. \& NIBLETT, C.L. Effects of wheat soilborne mosaic on several plant characters of winter wheat. Plant Disease Reporter 63:594-598. 1979.

PALMER, L.T. \& BRAKKE, M.K. Yield reduction in winter wheat infected with soilborne wheat mosaic virus. Plant Disease Reporter 59:469-471. 1975.

PRESTES, A.M. \& WIETHÖLTER, S. Efeito da virose do mosaic no rendimento da biomassa de cultivares de trigo em diferentes níveis de adubação nitrogenada. Fitopatologia Brasileira 18:293. 1993. (Resumo).

RECOMENDAÇÕES DA COMISSÃO SUL-BRASILEIRA DE PESQUISA DE TRIGO. XXX Reunião da Comissão SulBrasileira de Pesquisa de Trigo. Chapecó. 1998. p.82.

SHIRAKO, Y. Non-AUG translation initiation in a plant RNA virus: a forty-amino-acid extension is added to the $\mathrm{N}$ terminus of the soil-borne wheat mosaic virus capsid protein. Journal of Virology 72: 1677-1682. 1998.

WADSWORTH, D.F. \& YOUNG, H.C. A soil-borne wheat mosaic virus in Oklahoma. Plant Disease Reporter 37:27-29. 1953. 